\title{
ARMAZENAMENTO DE SEMENTES DE Erythrina velutina WILLD ${ }^{1}$
}

\author{
Kelina Bernardo Silva², Edna Ursulino Alves³, Edilma Pereira Gonçalves ${ }^{4}$, Riselane de Lucena Alcântara \\ Bruno $^{3}$ e Pablo Radamés Cabral de França ${ }^{5}$
}

\begin{abstract}
RESUMO - O trabalho teve como objetivo avaliar o efeito de diferentes embalagens e ambientes de armazenamento na manutenção da qualidade fisiológica de sementes de Erythrina velutina Willd.. O experimento foi conduzido no Laboratório de Análise de Sementes do Departamento de Fitotecnia do Centro de Ciências Agrárias da Universidade Federal da Paraíba (CCA-UFPB), localizado no município de Areia (PB). As sementes de Erythrina velutina Willd. foram coletadas embaixo de árvores matrizes, no mesmo município e levadas para o laboratório, onde se realizou a homogeneização e acondicionamento em embalagens de papel, pano e vidro e, posterior armazenamento em condições não controladas de laboratório $\left( \pm 25^{\circ} \mathrm{C}\right)$, geladeira $\left(6 \pm 2^{\circ} \mathrm{C}\right)$ e câmara fria $\left(4 \pm 2^{\circ} \mathrm{C}\right)$, por um período de 225 dias. Antes e após os intervalos de 45 dias foram retiradas amostras de cada embalagem e ambiente de armazenamento para avaliação das seguintes características: teor de água, emergência (porcentagem e índice de velocidade), comprimento e massa seca de epicótilo, hipocótilo e raiz das plântulas normais. O delineamento experimental utilizado foi inteiramente ao acaso com quatro repetições de 25 sementes para cada teste. As sementes de mulungu são ortodoxas e acondicionando-as nas embalagens de papel, pano ou vidro podem ser armazenadas nos ambientes de laboratório, geladeira e câmara fria, durante 225 dias sem perdas significativas na emergência das plântulas.

Palavras-chave: Mulungu, Germinação, Vigor, Embalagens e Ambientes.
\end{abstract}

\section{STORAGE OF Erythrina velutina WILLD. SEEDS}

\begin{abstract}
The objective of this experiment was to evaluate the effect of different packages and storage environments in maintainace of physiological quality of Erythrina velutina Willd seeds. The experiment was carried out in the Laboratory of Seed Analysis of Seeds in Department of Phytotecny in the Center of Agriculture Sciences at Federal University of Paraiba (CCA-UFPB), located in Areia, northeastern Brazil. The seeds of Erythrina velutina were collected under the matrix trees in the same city and taken to the laboratory, where it was carried out homogenization and packing in paper, cloth and glass packages and, posterior storage in non-controlled laboratory conditions $\left( \pm 25^{\circ} \mathrm{C}\right)$, refrigerator $\left(6 \pm 2^{\circ} \mathrm{C}\right)$ and cold chamber $\left(4 \pm 2^{\circ} \mathrm{C}\right)$, for a period of 225 days. Before and after the 45 - day intervals, samples were removed from each package and storage environment for evaluation of the following characteristics: water content, emergency test (percentage and speed rate); length and dry mass of epicotyle, hipocotyle and root of normal seedlings. The experimental design used was completely randomized with four replicates of 25 seeds for each test. E. velutina seeds are orthodox and by packing them in paper, cloth or glass packages, they can be stored in environments of laboratory, refrigerator and cold chamber for 225 days without significant loss in seedling emergency.
\end{abstract}

Keywords: Environments, Germination, Mulungu, Packing and Vigor.

\section{INTRODUÇÃO}

Erythrina velutina Willd. (Fabaceae) é popularmente conhecida como suinã, mulungu, canivete, corticeira, mulungu-da-catinga, pau-de-coral, sanaduí, sananduva (LORENZI, 2002). É uma espécie nativa da flora brasileira utilizada na medicina popular de algumas regiões do Nordeste brasileiro, como sudorífico, calmante, emoliente peitoral e anestésico local, embora a eficácia e segurança de seu uso ainda não tenham sido confirmadas cientificamente (LORENZI; MATOS, 2002).

Um dos aspectos que vêm sendo mais pesquisados é a qualidade fisiológica das sementes em decorrência

\footnotetext{
' Recebido em 18.01.2009 e aceito para publicação em 20.04.2011

² Doutorado em Agronomia pela Universidade Federal da Paraíba, UFPB, Brasil. E-mail: <kelinabernardo@yahoo.com.br>. ${ }^{3}$ Departamento de Fitotecnia, Universidade Federal da Paraíba, Centro de Ciências Agrárias -Campus II.E-mail: <ednaursulino@cca.ufpb.br> . ${ }^{4}$ Universidade Federal Rural de Pernambuco, UFRPE, Brasil. E-mail: <edilmapg@hotmail.com>.

${ }^{5}$ Programa de Pós-graduação em Agronomia da Universidade Federal da Paraíba, UFPB, Brasil. E-mail: <pabloradames@yahoo.com.br>.
} 
de mudanças degenerativas de origem bioquímica, fisiológica e física a que estão sujeitas após a sua maturação, associadas à redução do vigor (ALIZAGA et al., 1990).

O armazenamento de sementes é fundamental para a preservação da viabilidade e do vigor em nível aceitável no período entre a colheita e a semeadura (AZEVEDO et al., 2003). O principal objetivo do armazenamento é controlar a velocidade de deterioração, pois a qualidade da semente pode ser mantida com o mínimo de deterioração possível, através de técnica adequada (VIEIRA et al., 2001).

De acordo com Carvalho e Nakagawa (2000), o armazenamento das sementes sofre a influência de diversos fatores, como qualidade inicial, condições climáticas durante a maturação, grau de maturação no momento da colheita, teor de água, ataque de pragas, doenças e patógenos, grau de injúria mecânica, embalagem, e características do ambiente, ou seja, a temperatura e umidade relativa do ar.

A utilização de embalagens adequadas permite a conservação da qualidade das sementes, propiciando ou não, trocas de vapor d’água com o ar atmosférico (POPINIGIS, 1985). A decisão sobre a escolha da embalagem em que se vão acondicionar as sementes não é tão simples. As condições climáticas sob as quais a semente vai permanecer armazenada, o comportamento no armazenamento e características mecânicas da embalagem, bem como sua disponibilidade no comércio, são aspectos importantes a serem considerados no processo de decisão sobre o tipo de embalagem a ser usada (CARVALHO; NAKAGAWA, 2000).

As sementes de várias espécies podem ser armazenadas por longo período sem tratamento, como muitas leguminosas pioneiras, mas outras necessitam de ser preparadas para o armazenamento e exigem condições ambientais especiais. Assim, além do tratamento da própria semente, são necessários embalagens e ambientes apropriados. Os principais meios utilizados para o armazenamento de sementes são as câmaras fria, seca e fria-seca, que se adaptam à maioria das situações (VIEIRA et al., 2001).

Várias pesquisas com diferentes espécies já foram realizadas com o objetivo de estudar o comportamento das sementes em diversas embalagens e ambientes de armazenamento, definindo técnicas capazes de prolongar o período de conservação, como estudos com Peltophorum dubium (Spreng) Taubert (PEREZ et al., 1999), Cedrela fissilis Vell. (CORVELLO et al., 1999), Acacia polyphylla DC. (ARAÚJO-NETO et al., 2005), Nectandra sp. (HIRANO e POSSAMAI, 2005), entre outros.

Não foram encontrados estudos relacionados com o armazenamento de sementes Erythrina velutina. Por isso, o trabalho foi realizado com o objetivo de avaliar o efeito de diferentes embalagens e ambientes de armazenamento para manutenção da sua qualidade fisiológica.

\section{MATERIAL E MÉTODOS}

O experimento foi conduzido no Laboratório de Análise de Sementes do Departamento de Fitotecnia do Centro de Ciências Agrárias da Universidade Federal da Paraíba (CCA-UFPB), localizado no Município de Areia (PB).

As sementes de mulungu foram coletadas embaixo de árvores matrizes, no Município de Areia - (PB). Em seguida, foram levadas para o laboratório, onde foram homogeneizadas e acondicionadas em embalagens de papel, pano e vidro e armazenadas no laboratório em temperatura ambiente $\left( \pm 25^{\circ} \mathrm{C}\right)$, em geladeira $\left(6 \pm 2^{\circ} \mathrm{C}\right)$ e em câmara fria $\left(4 \pm 2^{\circ} \mathrm{C}\right)$, por um período de até 225 dias. Antes e após os intervalos de 45 dias, foram retiradas amostras de cada embalagem e ambiente de armazenamento para avaliação das características citadas a seguir.

Teor de água - foi determinado antes e após cada período de armazenamento, utilizando-se quatro subamostras de $3 \mathrm{~g}$ para cada tratamento. Essas subamostras foram colocadas em estufa a $105 \pm 3^{\circ} \mathrm{C}$ por 24 horas, seguindo as recomendações de Brasil (2009).

Teste de emergência - foi realizado em casa de vegetação, com quatro repetições de 25 sementes, semeadas em bandejas plásticas de 41 x 36 × 7,6cm de comprimento, largura e profundidade, respectivamente, contendo areia lavada. A umidade foi mantida por meio de irrigações diárias. A contagem do número de plântulas emergidas foi realizada a partir do terceiro dia, quando os cotilédones se encontravam acima do solo, finalizando no $15^{\circ}$ dia após a semeadura. Os resultados foram expressos em porcentagem.

Índice de velocidade de emergência (IVE) - este teste foi realizado juntamente com o teste de emergência, e a contagem das plântulas normais foi realizada 
diariamente, a partir do terceiro até o $15^{\circ}$ dia após a semeadura. O índice foi calculado utilizando-se a fórmula proposta por Maguire (1962).

\section{Comprimento e massa seca do epicótilo, hipocótilo} e raiz de plântulas - no final do teste de emergência, o epicótilo, o hipocótilo e a raiz primária das plântulas normais foram medidos com régua graduada em centímetros, sendo os resultados expressos em centímetros por plântula. Logo após as medições, as plântulas normais tiveram seus cotilédones removidos, as partes separadas com auxílio de tesoura e postas para secar em estufa regulada a $65^{\circ} \mathrm{C}$ por 48 horas. Decorrido esse período, foram pesadas em balança analítica com precisão de $0,001 \mathrm{~g}$.

O delineamento experimental utilizado foi o inteiramente ao acaso, com quatro repetições de 25 sementes para cada teste, em esquema fatorial $3 \times 3$ (embalagem x armazenamento). Os dados obtidos foram submetidos à análise de variância, e as equações de regressão foram ajustadas. Nas análises estatísticas, foi utilizado o programa SAEG, desenvolvido pela Universidade Federal de Viçosa (MG).

\section{RESULTADOS}

Os dados de temperatura e umidade relativa foram coletados diariamente, nos ambientes de armazenamento das sementes, durante o período do experimento, conforme a Figura 1.

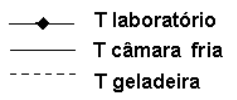

Os dados médios do teor de água das sementes de Erythrina velutina armazenadas em diferentes embalagens e ambientes não se ajustaram a modelos de regressão, pois, durante todo o período, a umidade permaneceu em torno de 7\%, ou seja, muito próxima do teor de água inicial, provavelmente devido à impermeabilidade do tegumento, que impediu a troca de umidade entre a semente e os ambientes de armazenamento.

De acordo com os dados da Figura 2, observou-se que houve diminuição na emergência das plântulas originadas a partir das sementes de E. velutina submetidas a períodos crescentes de armazenamento.

Quanto ao índice de velocidade de emergência das plântulas de E. velutina (Figura 3A), observou-se que os dados referentes às sementes armazenadas em laboratório e acondicionadas nas embalagens de pano e vidro não se adequaram a nenhum modelo de regressão, apresentando médias de 3,49 e 3,61, respectivamente, enquanto aquelas das embalagens de papel tiveram perda do vigor acentuada e comportamento linear descendente, ou seja, houve redução no índice de velocidade de emergência, de 4,29, no início do armazenamento para, 3,11 aos 225 dias de armazenamento.

Quando as sementes foram armazenadas em geladeira, apenas os dados daquelas acondicionadas em papel não se ajustaram aos modelos de regressão, apresentando média de 3,55. Aquelas das embalagens

U UR laboratório

$\square$ UR câmara fria

$\square$ UR geladeira

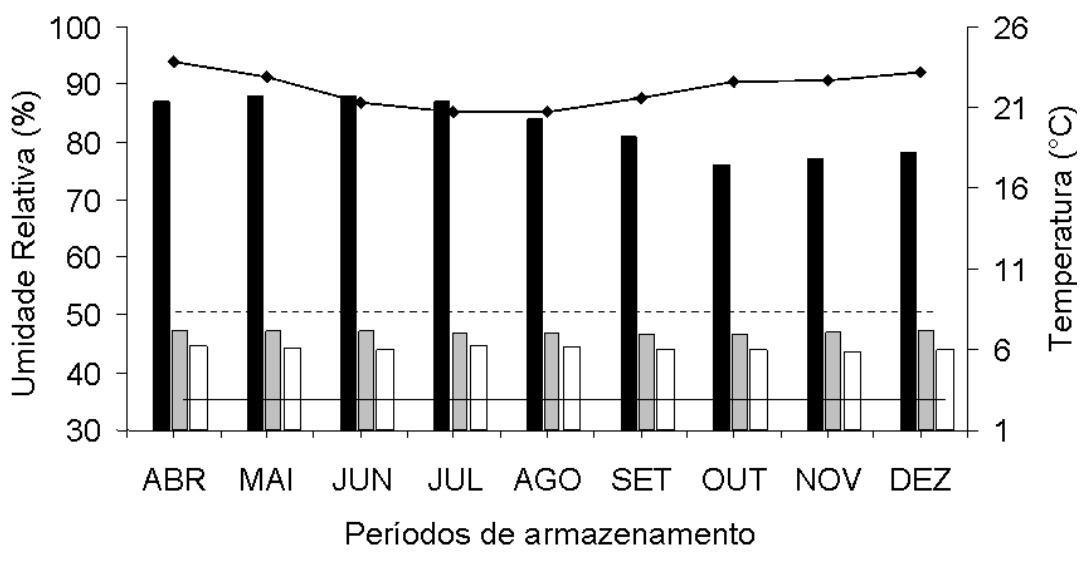

Figura 1 - Dados de umidade relativa (\%) e temperatura $\left({ }^{\circ} \mathrm{C}\right)$ dos ambientes de armazenamento entre abril a dezembro de 2006.

Figure 1 - Relative humidity (\%) and temperature $\left({ }^{\circ} \mathrm{C}\right)$ data in storage environment from April to December, 2006. 


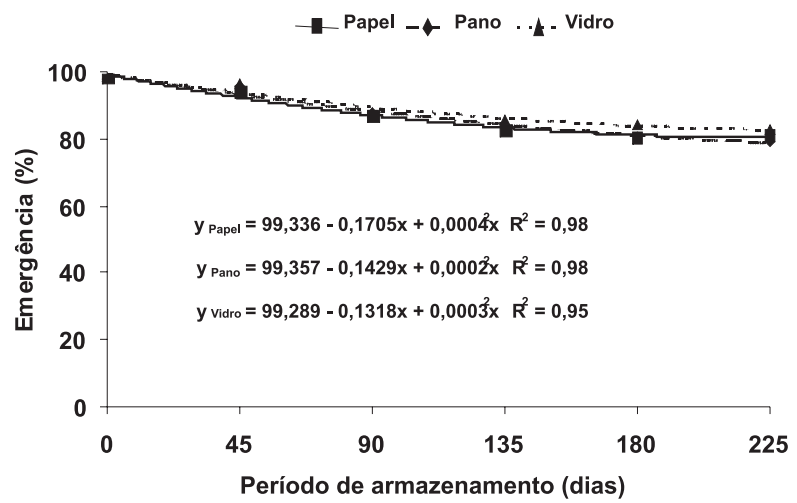

Figura 2 - Emergência de plântulas de Erythrina velutina oriundas de sementes acondicionadas em diferentes embalagens e armazenadas durante 225 dias.

Figure 2-Emergency Erythrina velutina seedlings from seeds packed in different bags and stored for 225 days.

de pano apresentaram perda linear do seu vigor, reduzindo a velocidade de emergência das plântulas de 4,20, no início, para 3,16 no final do armazenamento. Essa redução não foi observada quando as sementes foram acondicionadas nas embalagens de vidro, as quais apresentaram o vigor máximo $(4,37)$ aos 46 dias de armazenamento, que se reduziu após esse período (Figura 3B).

De acordo com os dados da Figura 3C, constatou-se que apenas as médias das sementes acondicionadas em embalagem de papel se adequaram ao modelo de regressão, onde se percebeu uma redução no índice de velocidade de 4,20 no início para 3,25 no final (225 dias) do armazenamento. Às sementes acondicionadas em embalagens de pano tiveram a média do índice de velocidade de emergência de 3,54, e aquelas oriundas da embalagem de vidro, de 3,82.

Os comprimentos dos epicótilos de plântulas de sementes acondicionadas em diferentes embalagens e armazenadas em laboratório e em câmara fria encontram-se na Figura 4A e B. Constatou-se que, no laboratório o comportamento foi similar em todas as embalagens testadas, mas houve uma redução ao longo do período de armazenamento. Na câmara fria, a redução no comprimento do epicótilo aconteceu nas sementes armazenadas nas embalagens testadas até os 135 dias. A partir desse dia, ocorreu um ligeiro crescimento.

Revista Árvore, Viçosa-MG, v.35, n.4, p.809-816, 2011
A

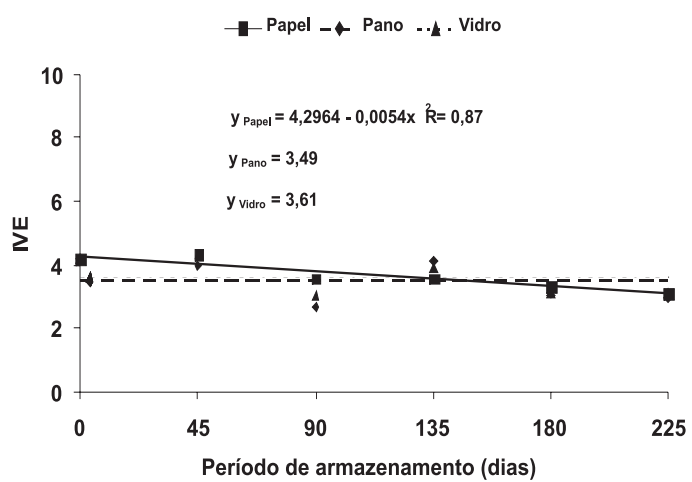

B

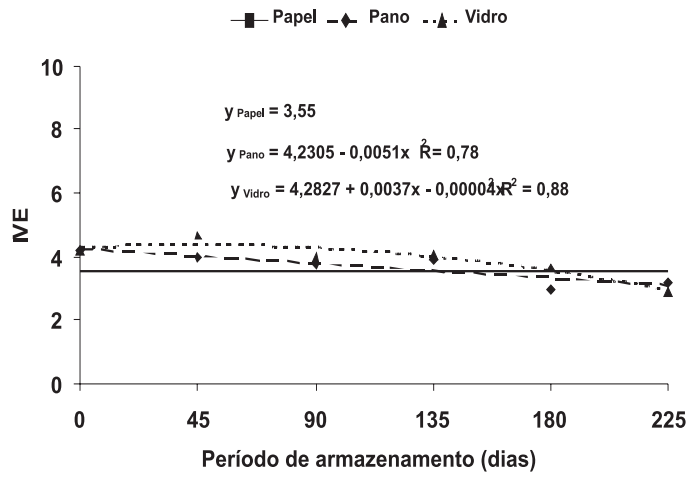

C

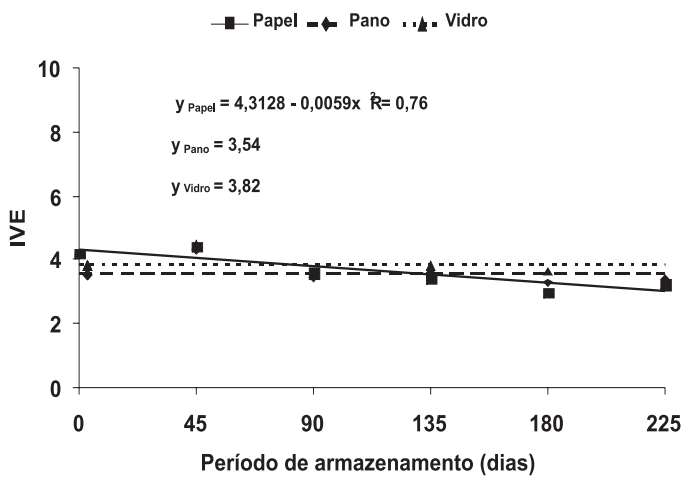

Figura 3 - Índice de velocidade de emergência de plântulas de Erythrina velutina oriundas de sementes acondicionadas em diferentes embalagens e armazenadas em (A) laboratório, (B) geladeira e (C) câmara fria durante 225 dias.

Figure 3-Emergence speed rate of emergence of Erythrina velutina grown from seeds packed in different containers and stored at (A) laboratory, (B) refrigerator and $(C)$ chamber for 225 days. 


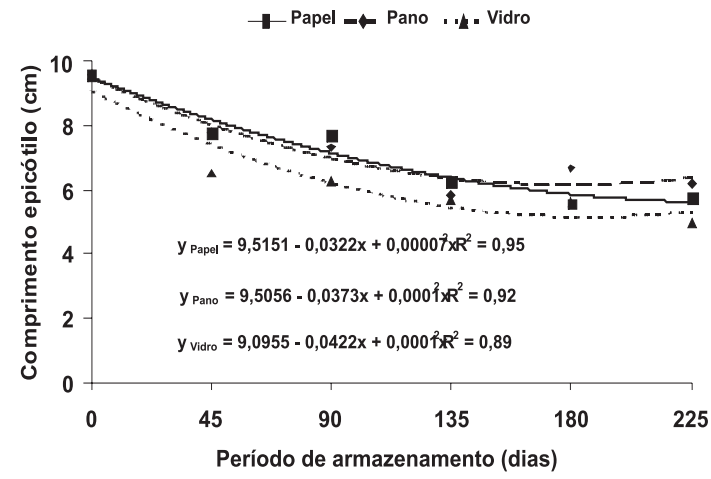

B

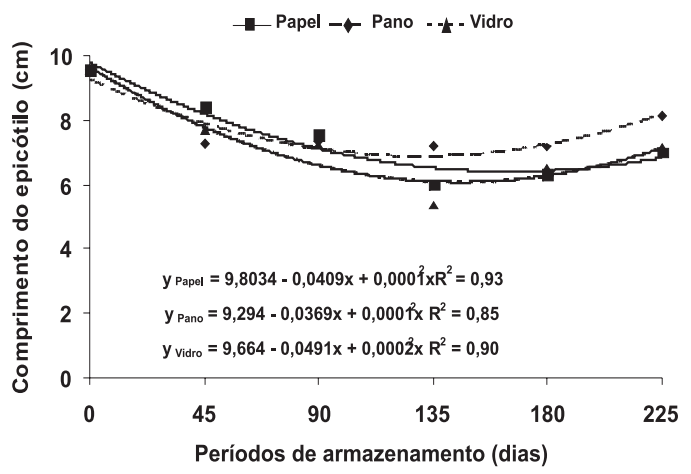

Figura 4-Comprimento do epicótilo de plântulas de Erythrina velutina oriundas de sementes acondicionadas em diferentes embalagens e armazenadas em (A) laboratório e (B) câmara fria durante 225 dias.

Figure 4-Epicotyl length of Erythrina velutina seedlings from seeds packed in different containers and stored at (A) laboratory and (B) cold chamber for 225 days.

Os dados das sementes acondicionadas nas embalagens de pano e vidro não se adequaram ao modelo de regressão, com comprimento médio do hipocótilo de 5,48 e 6,24cm, respectivamente. Aquelas armazenadas em embalagens de papel ajustaram-se ao modelo quadrático de regressão, alcançando comprimento máximo do hipocótilo $(6,34 \mathrm{~cm})$ aos 63 dias de armazenamento, depois do qual ocorreu uma redução (Figura 5).

Os dados de comprimento da raiz primária de plântulas provenientes de sementes dos diferentes ambientes de armazenamento (Figura 6) permitem afirmar que o melhor resultado $(14,08 \mathrm{~cm})$ foi obtido com aquelas que estavam na geladeira aos 112 dias, enquanto as raízes das plântulas de sementes armazenadas em laboratório tiveram o comprimento máximo $(11,18 \mathrm{~cm})$ aos 81 dias.

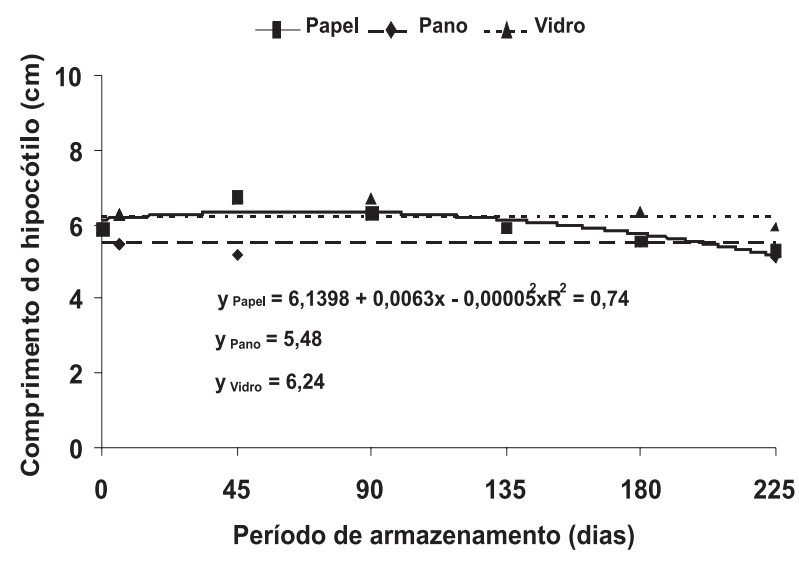

Figura 5-Comprimento do hipocótilo de plântulas de Erythrina velutina oriundas de sementes acondicionadas em diferentes embalagens e armazenadas em câmara fria durante 225 dias.

Figure 5-Hypocotyl length of seedlings of Erythrina velutina from seeds packed in different containers and stored in cold storage for 225 days.

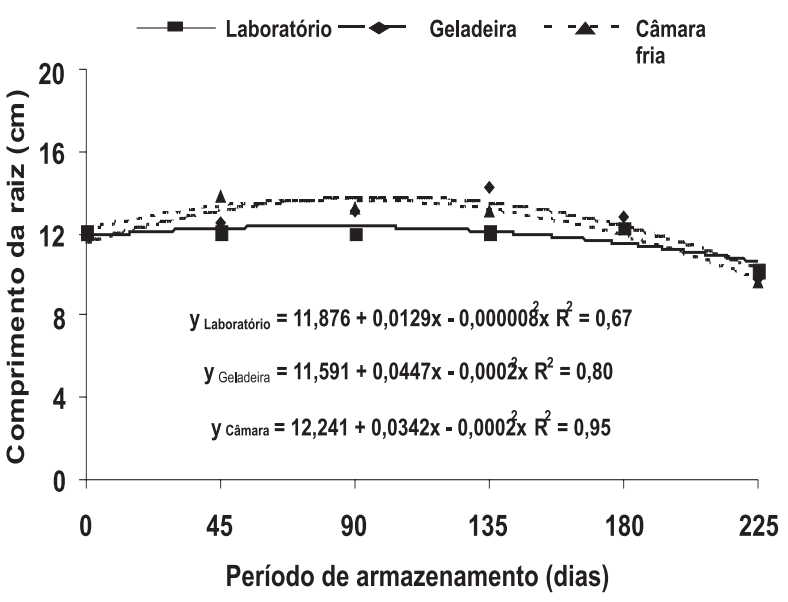

Figura 6 - Comprimento da raiz primária de plântulas de Erythrina velutina oriundas de sementes armazenadas em diferentes ambientes durante 225 dias.

Figure 6 - Length of primary roots of Erythrina velutina seedlings from seeds stored in different environments for 225 days.

Com relação à massa seca do hipocótilo das plântulas (Figura 7A), constatou-se que os dados referentes às sementes armazenadas em laboratório e acondicionadas nas embalagens de pano e papel se adequaram ao modelo quadrático de regressão, apresentando redução na massa seca ao longo do armazenamento.

Revista Árvore, Viçosa-MG, v.35, n.4, p.809-816, 2011 

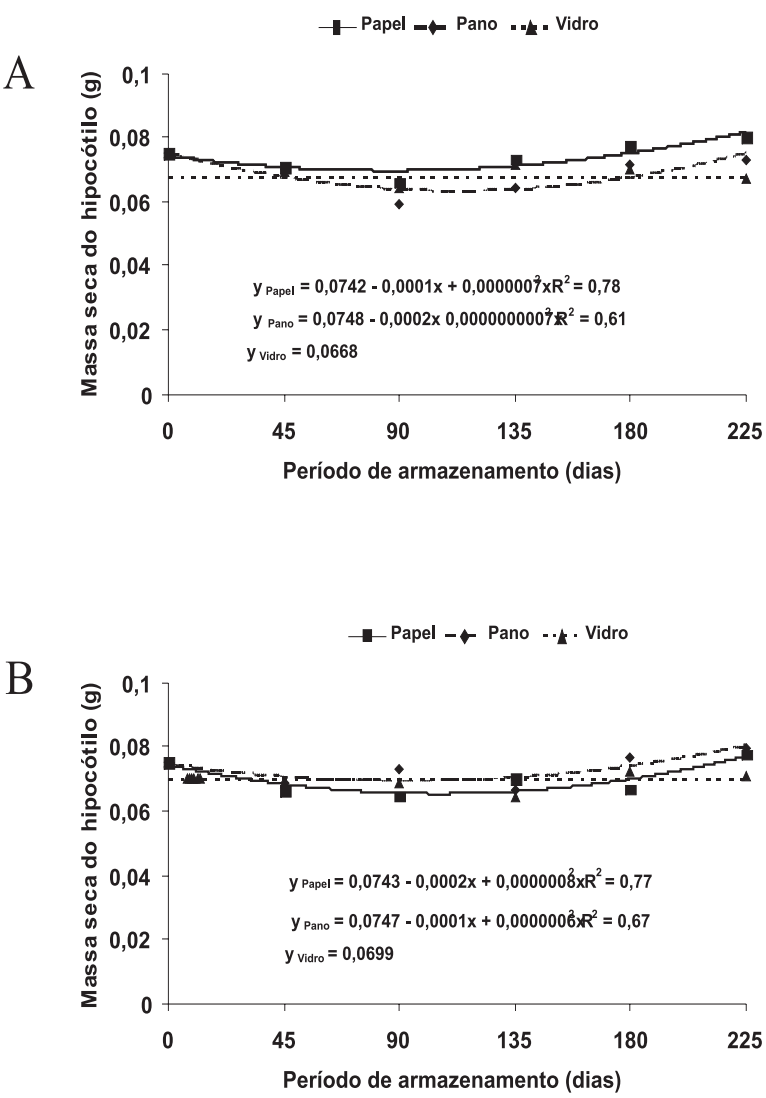

C

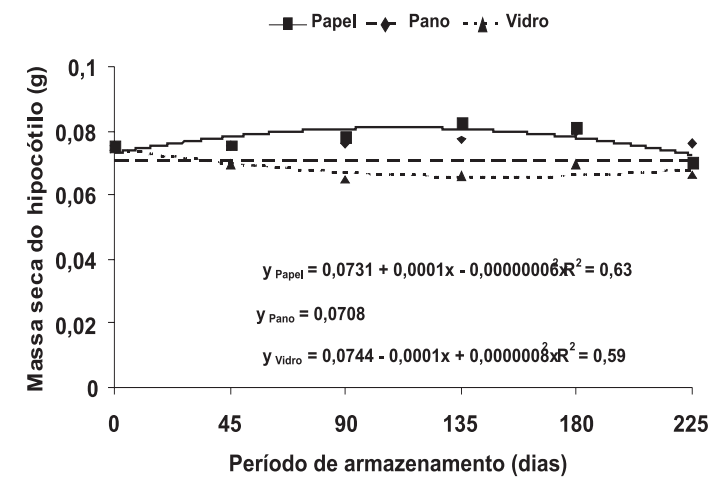

Figura 7 - Massa seca do hipocótilo de plântulas de Erythrina velutina oriundas de sementes acondicionadas em diferentes embalagens e armazenadas em (A) laboratório e (B) geladeira e (C) câmara fria durante 225 dias.

Figure 7-Hypocotyl dry mass of seedlings of Erythrina velutina from seeds packed in different containers and stored at (A) laboratory and (B) refrigerator and (C) cold chamber for 225 days.

Revista Árvore, Viçosa-MG, v.35, n.4, p.809-816, 2011
Para essa variável, os ambientes e embalagens utilizados proporcionaram as mesmas condições de conservação, de forma que os dados obtidos não diferiram estatisticamente entre si.

Quanto às sementes armazenadas em geladeira, apenas os dados daquelas acondicionadas em vidro não se ajustaram aos modelos de regressão, apresentando média de $0,067 \mathrm{~g}$. As plântulas originadas das sementes acondicionadas nas embalagens de papel e pano também apresentaram redução no conteúdo de massa seca do hipocótilo ao longo do armazenamento (Figura 7B). Analisando-se os dados da Figura 7C, constatou-se que apenas as médias das sementes acondicionadas na embalagem de pano 0,0708g não se adequaram ao modelo de regressão. Para as sementes acondicionadas nas embalagens de papel e vidro, os dados se ajustaram a modelo quadrático, com redução da massa seca ao longo do armazenamento.

\section{DISCUSSÃO}

As sementes de Erythrina velutina Willd. possuíam teor médio de água de 7\%, o qual está de acordo com os relatos de Bradbeer (1988), em que para a maioria das sementes ortodoxas o teor de água é de cerca de 5 a $20 \%$, com base em sua massa fresca.

Os resultados de emergência obtidos devem-se, provavelmente, à deterioração das sementes por oxidação, pois, apesar de o teor de água não ter se alterado, foi suficiente para permitir uma respiração mais elevada.

A umidade presente no ar pode promover o reinício das atividades do embrião, caso o oxigênio e a temperatura sejam suficientes para que tal processo aconteça, acelerando, dessa forma, a perda do vigor das sementes (TOLEDO; MARCOS-FILHO, 1977).

Observa-se que os ambientes e embalagens utilizados não foram eficientes na conservação do vigor das sementes, provavelmente por permitirem que tivessem uma elevada taxa respiratória. A sensibilidade das sementes ao processo de deterioração, em determinado ambiente, tem sido atribuída à constituição genética (BRACCINI et al., 2001), pois há diferenças entre espécies, cultivares dentro de uma mesma espécie, e entre as sementes de um mesmo lote (ROSS, 1982; POPINIGIS, 1985).

Resultados similares foram encontrados para as sementes de juerana-verdadeira (Parkia pendula Benth. ex. Walp.) durante dois meses de 
armazenamento, em que o ambiente com refrigeração e o acondicionamento das sementes em embalagens porosas e impermeáveis afetaram o vigor das plântulas (ALBUQUERQUE et al., 2005). Em sementes de Araucaria angustifolia (Bertol.) Kuntze, as plântulas originadas de sementes armazenadas em condições normais de ambiente apresentaram maior comprimento da parte aérea em relação às acondicionadas sob temperatura controlada, especialmente aos 60 e 120 dias (CAÇOLA et al., 2006).

O comprimento da parte aérea de plântulas de ipêamarelo (Tabebuia serratifolia (Vahl.) Nich.), oriundas de sementes acondicionadas em sacos de papel e armazenadas em laboratório, reduziu-se após 120 dias (SOUZA et al., 2005). Porém, sementes de moringa (Moringa oleifera Lam.) armazenadas em ambiente natural por seis meses ainda originaram plântulas vigorosas (BEZERRA et al., 2004).

Os dados de massa seca do epicótilo e das raízes das plântulas originadas de sementes acondicionadas em diferentes embalagens e armazenadas em vários ambientes não se ajustaram aos modelos de regressão, indicando que essa característica não sofreu influência das embalagens e ambientes utilizados para o armazenamento das sementes.

As sementes de Myracrodruon urundeuva (Engl.) são mais bem conservadas no ambiente natural de laboratório $\left(27,7^{\circ} \mathrm{C}\right.$ e UR de $62,8 \%$ ), durante seis meses em embalagem metálica, porém, para períodos de um ano, a indicação foi a câmara $\left(15,1^{\circ} \mathrm{C}\right.$ e $\left.74,7 \% U R\right)$, independente do tipo de embalagem utilizada (CALDEIRA e PEREZ, 2005).

A condição de armazenamento mais adequada para a conservação de sementes de Apeiba tibourbou Aubl. com menor perda de vigor foi o ambiente natural de laboratório, na embalagem de saco de polietileno por 180 dias (FERREIRA et al., 2010).

\section{CONCLUSÕES}

As sementes de mulungu são ortodoxas e, acondicionadas nas embalagens de papel, pano ou vidro, podem ser armazenadas nos ambientes de laboratório, geladeira e câmara fria, durante 225 dias, sem perdas significativas na emergência das plântulas.

\section{REFERÊNCIAS}

ALBUQUERQUE, M. C. F. et al. Armazenamento de sementes de Parkia pendula Benth. ex Walp. Informativo ABRATES, v.15, p.313, 2005.

ALIZAGA, R. L.; MELLO, V. D. C.; SANTOS, D. S. B.; IRIGON, D. L. Avaliação de testes de vigor em sementes de feijão e suas relações com a emergência em campo. Revista Brasileira de Sementes, v.12, n.2, p.44-58, 1990.

ARAÚJO-NETO, J. C. et al. Armazenamento e requerimento fotoblástico de sementes de Acacia polyphylla DC. Revista Brasileira de Sementes, v.27, n.1, p.15-124, 2005.

AZEVEDO, M. R. Q. A. et al. Influência das embalagens e condições de armazenamento no vigor de sementes de gergelim. Revista Brasileira de Engenharia Agrícola e Ambiental, v.7, n.3, p.519-524, 2003.

BEZERRA, A. M. E. et al. Avaliação da qualidade das sementes de Moringa oleifera Lam. durante o armazenamento. Ciência e Agrotecnologia, v.28, n.6, p.1240-1246, 2004.

BRACCINI, A. L.; BRACCINI, M. C. L.; SCAPIM, C. A. Mecanismos de deterioração das sementes: aspectos bioquímicos e fisiológicos. Informativo ABRATES, v.11, n.1, p.10-15, 2001.

BRADBEER, J. W. Seed dormancy and germination. Glasgow: Blackie Son. 1988. 146p.

BRASIL. Ministério da Agricultura, Pecuária e Abastecimento. Regras para análise de sementes. Secretaria de Defesa Agropecuária. Brasília: MAPA/ACS, 2009. 399p.

CAÇOLA, A. V. et al. Qualidade fisiológica de sementes de Araucaria angustifolia (Bertol.) Kuntze submetidas a diferentes condições de armazenamento e a escarificação. Ciência Florestal, v.16, n.4, p.391-398, 2006.

CALDEIRA, S. F.; PEREZ, S. C. J. G. A.

Viabilidade de sementes armazenadas de aroeira, Myracrodruon urundeuva (Engl.) Fr.All.

Informativo ABRATES, Pelotas, v.15, p.305-305, 2005.

Revista Árvore, Viçosa-MG, v.35, n.4, p.809-816, 2011 
CARVALHO, N. M.; NAKAGAWA, J. Sementes: ciência, tecnologia e produção. 4.ed. Jaboticabal: FUNEP, 2000. 588p.

CORVELLO, W. B. V. et al. Época de colheita e armazenamento de sementes de cedro (Cedrela fissilis Vell.). Revista Brasileira de Sementes, v.21, n.2, p.28-34, 1999.

FERREIRA, E. G. B. S. et al. Vigor das sementes de Apeiba tibourbou Aubl. sob difrentes condições de armazenamento e embalagens. Ciência Florestal, v.20, n.2, p.295-305, 2010.

PEREZ, S. C. J. G. A.; FANTI, S. C.; CASALI, C. A. Influência do armazenamento, substrato, envelhecimento precoce e profundidade de semeadura na germinação de canafístula. Bragantia, v.58, n.1, p.57-68, 1999.

HIRANO, E.; POSSAMAI, E. Influência do ambiente de armazenamento na conservação da semente de cinco espécies de Lauraceae. Informativo ABRATES, v.15, p.272, 2005.

LORENZI, H. Árvores brasileiras: manual de identificação e cultivo de plantas arbóreas do Brasil. Nova Odessa: Instituto Plantarum, 2002. 384p.
LORENZI, H.; MATOS, F. J. A. Plantas medicinais no Brasil: nativas e exóticas cultivadas. Nova Odessa: Instituto Plantarum, 2002.512p.

MAGUIRE, J. D. Speed of germination-aid in selection and evaluation for seedling emergence and vigor. Crop Science, v.2, n.2, p.176-177, 1962.

POPINIGIS, F. Fisiologia da semente. Brasília: AGIPLAN, 1985. p.145-156.

ROSS, E. E. Induced genetic changes in sedd germplasm during storage. In: KHAN, A. A. (Ed.). The physiology and biochemistry of seed development, dormancy and germination. Amsterdam: Elsevier Biomedical Press, 1982. p.409-434.

SOUZA, V. C.; BRUNO, R. L. A.; ANDRADE, L. A. Vigor de sementes armazenadas de ipê-amarelo Tabebuia serratifolia (Vahl.) Nich. Revista Árvore, v.29, n.6, p.833-841, 2005.

TOLEDO, F. F.; MARCOS-FILHO, J. Manual de sementes: tecnologia da produção. São Paulo: Agronômica Ceres, 1977. 224p.

VIEIRA, A. H. et al. Técnicas de produção de sementes florestais. Rondônia: 2001. p.1-4. (EMBRAPA-CPAF, 205). 